\title{
Project Management in Libraries: On Time, On Budget, On Target. By Carly Wiggins
} Searcy. Chicago: ALA Editions, 2019.136 pp. Index. Softcover. \$54.99.

In recent years, within the library and archives community emphasis on the value of project management has increased. This book by Carly Wiggins Searcy serves as an excellent, high-level introduction to project management and its core principles and concepts. And, at only 136 pages, it is a quick read. The content is solid and based on established project management best practices, and the discussions of each point are brief and effectively introduce the concept in an easily digestible form. The chapters are also well organized by concept, resulting in a near linear discussion of the project management process, from project development to closeout.

In the preface, Searcy introduces the many types of projects found in libraries, both large and small, demonstrating where project management principles and practice can be applied. She then discusses her own background as a certified project management professional and as a librarian with over 20 years of library experience, including how she became a project manager. The book begins with an overview of projects, project management, examples of projects, a discussion of why project management is important, and statistics for projects that were completed on time and within budget. The role of project managers is also discussed, including the five process groups or phases of a project: initiating, planning, executing, monitoring and controlling, and closing. Searcy emphasizes that this book focuses on practical project management and is not intended to serve as a complete overview of the Project Management Institute's 47 project management processes. Rather, Searcy focuses on "building knowledge and skills and using tools and techniques for better project management in libraries" and encourages the adaptation of these concepts to individual projects (p. 4).

In the second chapter, Searcy discusses the characteristics of project managers, focusing on several key aspects including being tenacious, collaborative, and ethical. Here, she also includes a brief discussion of the Project Management Institute's ethical decisionmaking framework, which guides project managers to balance competing needs and desires through assessment, identifying and analyzing alternatives, and examining the impact of application and action.

Chapter 3 is particularly valuable, serving as a primer on basic meeting management. It includes clear, detailed guidance on how to facilitate all types of meetings, not just those associated with project management activities. This chapter also includes sample checklists for preparing for and facilitating meetings, as well as handling meeting follow-up activities. Next, in a section on project management tools, Searcy provides guidance on how to evaluate the project management needs of one's institution, find existing institutional tools, and assess which tool would be the best choice based on the needs of your institution. A brief discussion of current proprietary, low-cost, and open source tools follows.

After addressing all of these overarching aspects of project management, Searcy turns to the issues of project initiation and launch, including best practices for creating a project charter. The project charter is the guiding document for a project, defining the scope of 
the project and project deliverables, and identifying resources required to accomplish the project. A brief discussion of the roles of existing documentation, environmental factors, organizational assets, and individual and group roles follows. The eight elements of the project charter-purpose, objectives, success criteria, requirements, constraints, risk, timeline, and cost estimates-are defined with brief examples of statements associated with each element.

Over the course of several chapters, Searcy discusses the development and implementation of the project plan as well as best practices for managing the execution of a project. Project plan implementation includes identifying the project's scope, goals, deliverables, and metrics to be collected; creating a budget; documenting changes; establishing a schedule; identifying stakeholders and project team members and the roles each will play; and addressing risk management concerns by identifying potential risks and managing them within the project. The execution phase of a project includes aspects such as project personnel management (e.g., team management), monitoring project activities, communication strategies, and closing activities. Searcy discusses the importance of each of these activities and provides guidance for avoiding common pitfalls in these areas.

This book serves as a solid high-level introduction to project management, explaining the essential concepts in a clear, concise manner. Searcy includes examples of documents and templates for selected activities, some of which will be useful to both new and seasoned project managers. The meeting checklist, responsibility assignment matrix, and communication plan can be easily adapted for use in a wide range of projects and applications. However, more examples of documentation, particularly of the project charter and project plan, would have added greatly to the usefulness of this book. For examples of these documents, readers will need to turn to other sources such as general project management resources, resources based on a specific project type, or institutional resources. Overall, Searcy shows a command of the project management process and clearly explains the basic concepts and principles of project management in an approachable and authoritative manner that will appeal to those unfamiliar with project management concepts and best practices.

Laura Drake Davis

Digital Project Specialist

Library of Congress 